Western University

Scholarship@Western

Aboriginal Policy Research Consortium International (APRCi)

2000

\title{
Adapting Violence Rehabilitation Programs for the Australian Aboriginal Offender
}

Peter Mals

Darwin Urban Mental Health Services

Kevin Howells

University of South Australia

Andrew Day

University of South Australia

Guy Hall

Murdoch University

Follow this and additional works at: https://ir.lib.uwo.ca/aprci

Part of the Criminology and Criminal Justice Commons

Citation of this paper:

Mals, Peter; Howells, Kevin; Day, Andrew; and Hall, Guy, "Adapting Violence Rehabilitation Programs for the Australian Aboriginal Offender" (2000). Aboriginal Policy Research Consortium International (APRCi). 424.

https://ir.lib.uwo.ca/aprci/424 
This article was downloaded by: [University of Western Ontario]

On: 30 October 2012, At: 09: 18

Publisher: Routledge

Informa Ltd Registered in England and Wales Registered Number: 1072954

Registered office: Mortimer House, 37-41 Mortimer Street, London W1T 3J H, UK

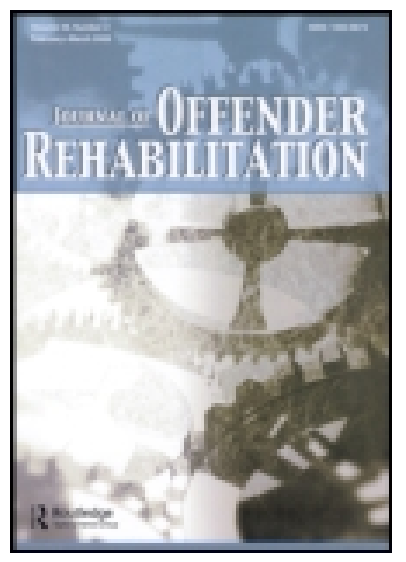

\section{J ournal of Offender Rehabilitation}

Publication details, including instructions for authors and subscription information:

http:// www. tandfonline.com/loi/ wjor20

\section{Adapting Violence Rehabilitation Programs for the Australian Aboriginal Offender}

Peter Mals ${ }^{a}$, Kevin Howells ${ }^{b}$, Andrew Day ${ }^{b} \&$ Guy Hall ${ }^{c}$

a Darwin Urban Mental Health Services, Northern

Territory, Darwin, Australia

${ }^{b}$ University of South Australia

c School of Law, Murdoch University

Version of record first published: 12 Oct 2008.

To cite this article: Peter Mals, Kevin Howells, Andrew Day \& Guy Hall (2000):

Adapting Violence Rehabilitation Programs for the Australian Aboriginal Offender, J ournal of Offender Rehabilitation, 30:1-2, 121-135

To link to this article: http:/ / dx.doi.org/ 10.1300/ / 076v30n01_08

\section{PLEASE SCROLL DOWN FOR ARTICLE}

Full terms and conditions of use: http://www.tandfonline.com/page/termsand-conditions

This article may be used for research, teaching, and private study purposes. Any substantial or systematic reproduction, redistribution, reselling, loan, sub-licensing, systematic supply, or distribution in any form to anyone is expressly forbidden.

The publisher does not give any warranty express or implied or make any representation that the contents will be complete or accurate or up to date. The accuracy of any instructions, formulae, and drug doses should be 
independently verified with primary sources. The publisher shall not be liable for any loss, actions, claims, proceedings, demand, or costs or damages whatsoever or howsoever caused arising directly or indirectly in connection with or arising out of the use of this material. 
Race, Ethnicity, Sexual Orientation, Violent Crime: The Realities and the Myths. Pp. 121-135.

E 2000 by The Haworth Press, Inc. All rights reserved.

\section{Adapting Violence Rehabilitation Programs for the Australian Aboriginal Offender}

PETER MALS

Darwin Urban Mental Health Services, Darwin, Northern Territory, Australia

KEVIN HOWELLS

University of South Australia

ANDREW DAY

University of South Australia

GUY HALL

School of Law, Murdoch University

ABSTRACT In this paper the authors address the question of how treatment and rehabilitation programs for violent offenders might be modified to more appropriately meet the needs of different cultural groups and improve treatment responsivity. The focus of the paper is on the needs of Aboriginal violent offenders in an Australian context, although the themes have relevance to treatment programs internationally. Two broad sources of information are used: the published literature relating to violent offending in Aboriginal people in Australia, and a small-scale interview-based qualitative survey of service providers with particular experience in this area. The evidence suggests there may be some distinctive features to Aboriginal violent offending. Suggestions are made on how programs can be more responsive to Aboriginal offender needs, thereby improving treatment and rehabilitation outcomes. [Article copies available for a fee from The Haworth Document Delivery Service: 1-800-342-9678. E-mail address: getinfo@haworthpressinc.com <Website: http://www.haworthpressinc.com>]

KEYWORDS Aboriginal, rehabilitation, violence, offender treatment 
Many correctional systems now implement treatment and rehabilitation programs aimed at reducing the likelihood of future violence in violent offenders. These programs often are labeled as "Anger Management" or "Alternatives to Violence" and typically take a skills approach to enabling violent offenders to develop alternative reactions to provocation and situations which have previously elicited violence (Howells, 1996, Novaco, 1997). Many of these programs are provided on a substantial scale. In Western Australia, for example, more than 500 violent offenders annually complete a 20 hour "Skills Training and Aggression Control" program provided throughout the state, in urban and remote rural areas, by the Ministry of Justice. Whilst the evidence for the general effectiveness of anger management programs is reasonable (Edmondson and Conger, 1996; Beck and Fernandez, 1998) much needs to be done in assessing the effects and impact of such programs with seriously violent offender populations (Watt and Howells, 1998).

The more general issue of whether offender rehabilitation programs work has been an important and controversial debate in penology for some years. There appears to be an emerging consensus that rehabilitation can have a significant impact on recidivism, providing rehabilitation programs have certain features (Losel, 1996; McGuire, 1995). Amongst the features of more effective programs are the principles of risk, needs and responsivity outlined by Andrews and Bonta (1994). They argue that the programs which promote the best outcomes are programs which match treatment to the offender's level of risk and need, and are delivered in "a style and mode that is consistent with the ability and learning style of the offender" (Andrews and Bonta, 1994, p. 177). Howells, Watt, Hall and Baldwin (1997) have also set out a number of requirements for effective treatment programs for violent offenders. Among these, they stressed the importance of population-focused needs assessment, as a means of ensuring that the content and format of interventions will be attuned to the characteristics of the group receiving treatment.

The present paper addresses an aspect of the responsivity principle which is particularly relevant in an Australasian context: Aboriginality. Howells et al. (1997) note that, in the geographical area in which they were working (Western Australia), Aboriginal offenders form a sizable, and disproportionate, proportion of the offender population. They question whether anger management programs are responsive to the needs of Aboriginal offenders, and whether existing programs are equally effective for Aboriginal and nonAboriginal participants. Specifically, Howells et al. (1997) focus on the possibility that there may be significant cultural differences in definitions, expectations and norms relating to the expression and control of anger and violence. In a review of the mental health issues relating to Aboriginality, Raphael and Swan (1997) argue that it is essential to take into account the 
historical context and social and cultural frameworks in which Aboriginal people live. The violent behavior involved in Aboriginal offences may also be distinctive in terms of its overt patterns and functional characteristics. If this is the case, for programs to achieve optimal outcomes, they will need to be designed and delivered in ways that have specific relevance for Aboriginal offenders.

This paper explores the above issues in two ways. In the first section the relevant criminological data are assessed for what they reveal about the extent and nature of Aboriginal violent offending. We draw heavily on the Western Australian data of Harding, Broadhurst, Ferrante and Loh (1995) to examine whether Aboriginal violent offending is distinctive from non-Aboriginal violent offending. In the second section we report the findings of a survey of a number of Western Australia based human-services providers who have had extensive experience with Aboriginal offenders. Where relevant, these findings are supplemented by insights gained from structured interviews with a small sample of violent Aboriginal offenders. Finally suggestions are made as to how anger management programs for violent offenders might become more responsive to Aboriginal needs. Whilst much of the material has been gathered from sources in Western Australia, we hope it is of relevance to those interested in programs with Aboriginal and Torres Strait Islander people across Australasia, and will be of interest to those delivering anger management programs internationally.

\section{REVIEW OF CRIMINOLOGICAL DATA}

In order to examine the possibility that violent offending in Aboriginal offenders is distinct from violent offending in non-Aboriginals, we reviewed data from three areas: the prevalence of offending, offender characteristics and victim characteristics.

\section{Prevalence of Violent Offending in Indigenous Australians}

As a result of the Royal Commission into Aboriginal Deaths in Custody it is now common knowledge that indigenous people are grossly over-represented in Australian prisons. Walker and McDonald (1995) reported that in 1992 indigenous people made up 1-2\% of the Australian population but accounted for $14 \%$ of the prison population. Nationally, indigenous people were being imprisoned at 13 times the rate of non-indigenous people with ratios varying across the States and Territories.

Levels of indigenous representation within respective offence categories have been less well investigated. Walker and McDonald's 1992 data (1995) 
indicated that indigenous people were over-represented in almost all categories of offence, with particularly high levels for crimes of violence. For the omnibus category of "crimes against the person" these authors cited a ratio of 15.8:1. For more fine-grained categories of violence, the corresponding figures were as follows: homicide (11.7); assaults (29); and sexual offences (17.9). These figures run counter to the views of the past which tended to characterize Aboriginal offending as minor, trivial and of social nuisance value (see Broadhurst, 1987).

Harding, Broadhurst, Ferrante and Loh (1995) have provided Western Australian data on police charges for violent crimes in 1993. Within each category of offence, they calculated the percentage of the arrested who were Aboriginal. They found that for the omnibus category of "offences against the person" (which included sexual assaults), Aboriginals made up $40.3 \%$ of all persons charged. The corresponding figure for homicides was $45 \%$ and, for non-sexual assaults, also 45\%. Given that Aboriginal people made up about $2.7 \%$ of the Western Australian population at this time, the latter figures again confirm strong over-representation. It is possible that bias in police practices may have inflated the ratios to some extent, but this is unlikely to be a major factor where homicides and other serious offences are concerned. Harding et al. indicate that over-representation tends to increase as Aboriginal offenders progress further through the criminal justice system.

\section{Characteristics of Aboriginal Violent Offenders}

Harding et al.'s (1995) data from 1993 indicate that the great majority of Aboriginals charged with offences against the person were male (81.6\%). The same pattern is seen in the offender population as a whole: males are strongly predominant among perpetrators of homicide (Strang, 1993); assault (National Committee on Violence, 1989); and sexual assault (Salmelainen \& Coumelaros, 1993).

The Western Australian data reported by Harding et al. (1995) indicates that about $29 \%$ of apprehensions for offences against the person were made in the Perth metropolitan area. This figure closely matches the geographical distribution of the Aboriginal population, 28\% live in the Perth Metropolitan area.

Walker and McDonald (1995) reported that unemployment was associated with markedly higher rates of imprisonment in both non-Aboriginals and Aboriginals. Within the Aboriginal population, the unemployed were imprisoned at 20 times the rate of the employed. However, among the unemployed, Aboriginals were still imprisoned at nine times the rate of non-Aboriginals. These figures relate to wholesale imprisonment rates: there is very little information, however, linking economic factors directly to violent offending. Easteal (1993) examined unemployment within one specific category of ho- 
micides: those perpetrated by one intimate partner on another. Among Aboriginal offenders, $79 \%$ of such perpetrators were unemployed, while the rate of unemployment for Aboriginals in the general population was 35\%. In non-Aboriginal offenders, the unemployment rate was $48 \%$, while the national rate was 9\%. Again, the unemployed were strongly over-represented among offenders in both ethnic groups. These figures suggest that the association between economic disadvantage and wholesale crime rates also holds up for at least some types of violent crime.

There has been widespread discussion in the literature about the potential contribution of alcohol misuse to violent offending (Ward and Baldwin, 1997), but data relating to alcohol-violence links in different cultural and ethnic groups is limited in scope. For a discussion of cultural aspects see National Symposium on Alcohol Misuse and Violence (1994a). This latter report makes the point that the socio-economic position of minorities may be a better guide to alcohol use and alcohol related violence than culture/ethnicity per se. Strang's (1993) nationwide study of homicides examined whether the offender had been under the influence of alcohol at the time. She found that, overall, $75 \%$ of the perpetrators had been affected by alcohol but that the percentage of Aboriginal offenders so affected was about twice that of the non-Aboriginals. Easteal's (1993) study of homicides between intimate partners also examined whether or not the offender had consumed alcohol immediately before the killing. She found that among Aboriginal offenders, 89\% were so affected whereas the corresponding figure for non-Aboriginal offenders was $65 \%$. Hazelhurst (1987) has suggested that drinking could be a factor in up to 90 per cent of all Aboriginal dealings with the justice system. Lincoln and Wilson (1994) described studies showing that whilst Aboriginal drinking levels are actually lower than for the general population, there is "high incidence of dangerous consumption levels," particularly among young men (p. 62).

\section{The Victims of Aboriginal Violent Offenders}

Harding et al. (1995) have provided a breakdown of offences against the person by race of victim and perpetrator. In non-Aboriginal offenders, victim selection is strongly intra-racial: in virtually all categories of violent offence, the numbers of Aboriginal victims are very low. The pattern is far more complex for offences committed by Aboriginals. The same intra-racial pattern is seen in sexual offences ( $71 \%$ of victims Aboriginal) and in homicides (73\%). In assaults though, approximately half the victims were non-Aboriginal $(49 \%)$ while for robbery, the pattern was reversed, with the great majority of victims $(95 \%)$ being non-Aboriginal.

Harding et al. (1995, p. 22) also provided a breakdown by gender and race of the victims of violent offences reported to the Western Australian police in 
1993. Among non-Aboriginal victims, the majority are males (59\%). Among Aboriginal victims, the pattern is reversed, with the majority $(68 \%)$ being female. This sex by race interaction is statistically significant. Harding et al. (1995) have also reported data on spousal violence specifically (again based on complaints to police). As would be expected, the perpetrators of such offences were predominantly the husbands (around 89\%) in both racial groups. Comparisons between Aboriginal and non-Aboriginal victims in terms of spouse-perpetrated offences show that spouses are responsible for a markedly higher proportion of the violence directed at Aboriginal victims. In homicides, for example, spouse-perpetrators accounted for $35.5 \%$ of offences against Aboriginals but only $19.8 \%$ of those against non-Aboriginals. In "serious assaults," the corresponding figures were $39.5 \%$ and $7.5 \%$. In common assaults, the figures were $33.9 \%$ and $6.8 \%$.

The above findings on homicides are compatible with Easteal's (1993) nationwide analysis of homicides by intimate partners. She reported that Aboriginal over-representation was far greater in this type of offence (Aboriginals accounting for $41 \%$ of perpetrators) than in non-intimate homicides (in which they accounted for $25 \%$ of perpetrators).

\section{Summary of Criminological Findings}

One important implication of the above figures, at the practical level, is that Aboriginal offenders can be expected to make up a significant proportion of the pool of candidates for prison-based violent-offender programs. In a Western Australian setting, all things being equal, this figure would be approximately $45 \%$, although these figures would vary across jurisdictions and geographical locations.

Violent Aboriginal offenders appear to be similar to non-Aboriginal offenders in that they are likely to be male, socio-economically disadvantaged, and under the influence of alcohol at the time of offence. Homicides and sexual assaults are predominantly intra-racial offences, which is consistent with data suggesting that the victim is likely to be either known to, or living in proximity to the perpetrator (Strang, 1993). Robbers of both races have a strong preference for non-Aboriginal victims. This is probably a reflection of economic realities: non-Aborigines are far more likely to be the proprietors of shops and other businesses that will be more lucrative targets for robbery.

\section{QUALITATIVE SURVEY OF EXPERT OPINION}

A purpose-designed semi-structured interview of 1-2 hours duration was conducted with 14 human services workers with experience relevant to reha- 
bilitation programs for Aboriginal offenders in Western Australia. Participants were asked for their views on how cultural differences, attitudes towards program facilitators, literacy and other factors might impact upon program delivery, and how programs could be made more responsive to Aboriginal needs. Those based in Perth were interviewed in person and the others in less accessible areas via telephone. Participants were predominantly, though not exclusively (10 out of 14), of Aboriginal background and varied greatly in terms of the agencies they represented, the nature of the services they had provided, and the remoteness of the communities in which they had chiefly worked. The sample included, for example, members of the Aboriginal Policy and Services Division of the Ministry of Justice, an Aboriginal facilitator of Skills Training and Aggression Control Programs, a worker from the Aboriginal Alternative Dispute Resolution Service, an Aboriginal Coordinator of cross-cultural training for the Ministry of Justice, a community corrections officer from a remote rural area with a high proportion of Aboriginal offenders, the Superintendent of a rural prison and the former coordinator of the "Ending Violent Offending" program for Aboriginal offenders.

\section{Predisposing Factors}

Aboriginal informants were in general agreement that Aboriginal male offenders (especially younger-generation, urban-dwellers) suffered from low self-esteem and a pervasive sense of frustration, anger and powerlessness. A number of informants used the same turn of phrase when commenting on self-esteem: "they feel like they're nothing." It was noted that urban males directed their anger and resentment not only toward mainstream society but often also toward their parents, whom they saw as having failed them. Informants saw these emotional problems as arising directly from colonisation and its legacy of social and economic marginalisation. It was suggested that male self-esteem had been particularly badly affected because men were finding it increasingly difficult to fulfill the role of family breadwinner, whereas women still had available to them the valued roles of child-carer and homemaker. Some informants noted that the above problems were less marked in remote communities where the men typically had a more secure sense of identity.

Only a few informants commented on the issue of Aboriginal men's attitudes to violence. There were suggestions that for some Aboriginal offenders, violence is the predominant way of resolving conflict, because this is the most frequent model they are exposed to as they grow up. It was noted that the forms of violence which are now prevalent depart considerably from that of tradition: under traditional law, violence was subject to group decisionmaking and was carefully prescribed and regulated; by contrast, present-day 
violence is a largely spontaneous matter, taking place independent of, and without reference to, any form of group authorisation.

Informants were divided in their views as to whether Aboriginal men were more likely than non-Aboriginal men to subscribe to an ideology of male dominance. Interestingly, Aboriginal commentators were more inclined than their non-Aboriginal counterparts to view Aboriginal men as chauvinistic. They saw this tendency as being in part an inheritance from traditional culture, in which men enjoyed higher overall status, even though women had a valued economic role and had considerable authority in circumscribed domains of spiritual life. The comment made by some informants was that, currently, men in remote communities tend to regard women largely as property. It was suggested that even among urban and fringe-dwellers, the prevailing attitude among men was that they were entitled to be "in charge." This attitude was not necessarily accepted by women, who were slowly becoming more influenced by feminist ideas. Feminist thought has nevertheless gained considerably less ground with Aboriginal women than with non-Aboriginals, in the view of those interviewed.

\section{Patterns and Precipitants of Aboriginal Violence}

Participants were unanimous in their view that the overwhelming majority of victims of Aboriginal violence were other Aboriginals. Most believed that females made up the majority of the victims and that many of these were the partners of the perpetrators. These informal perceptions are thus very much in keeping with the criminological data reviewed in the preceding section.

There was also strong consensus among informants as to the prevalence and importance of the following triggering or contextual factors in Aboriginal violence:

(i) inter-family feuds;

(ii) "jealousy" within intimate relationships; and

(iii) alcohol intoxication.

All informants viewed alcohol as an important contributing factor to $\mathrm{Ab}$ original violence. Those who had worked in remote areas observed that virtually all violent crimes by Aboriginal men were alcohol-related. Few informants offered any comment as to the mechanism by which alcohol and violence might be linked, other than to suggest that everyday conflicts were more likely to escalate into violent confrontations under the influence of alcohol.

Feuding between family groups was noted to be common across the full spectrum of Aboriginal communities. It was noted that feuds could originate from apparently trivial incidents (for example, an instance of foul-play in a 
football match). Once a feud has begun, family obligations may draw progressively more individuals into the hostilities. These conflicts can endure for many years and may span several generations of the families involved. A major perpetuating factor was seen to be the absence of any socially accepted way for the opposing camps to withdraw from the conflict: to give up the fight inevitably involves a loss of face. There was said to be a belief among males that one's sense of manhood hinges on achieving victory. It was suggested further that, in urban settings, family feuds may serve as a convenient conduit for the expression of the anger that arises from socio-economic marginalisation.

Jealousy, or suspicion of infidelity, was posited as a common precipitant of violence, which might be directed either at the female partner or at the other male implicated in the triangle. Non-Aboriginal informants noted that jealousy seemed to be construed somewhat differently among Aboriginal people. Some of the salient differences are as follows: jealousy within intimate relationships is so common in Aboriginal people as to be virtually normative; jealousy may be precipitated by very subtle nuances of non-verbal behaviour and others may well accept such cues as justifiable grounds for the jealous person's feelings and suspicions; expressions of jealousy ("jealousing") may be taken as an indication of caring by the jealous person's partner.

\section{Program Delivery Issues}

Opinion was divided as to whether treatment groups should be racially segregated or mixed. The principal argument in favour of segregation was that it would facilitate self-disclosure on the part of Aboriginal men: all members of the group would have a common cultural and socioeconomic background, would therefore feel more comfortable and be more likely to be open with each other. Some informants reported that when Aboriginal men had formed a small minority within a mixed treatment group they had tended to remain passive and withdrawn.

A further concern was that tribal men would feel intimidated or embarrassed by the more literate and English-fluent men from urban settings. On the other hand, informants who had actually conducted programs in remote areas noted that there had been a great deal of collaboration between the more and less verbally skilled members of the group. Of course, this kind of collaboration would be possible only where respective members of the group spoke the same Aboriginal language. It was argued therefore that the best plan for service delivery to remote-community Aborigines would be to run separate programs for each of the major language groups: ideally each program would be conducted in the local language.

A second argument put forward in favour of segregation was that it would allow for better targeting of treatment on issues of particular relevance to 
Aboriginal men. An opposing argument was that segregation might lead Aboriginal offenders to feel as if they were being singled out by the system as being particularly violent or out-of-control. It was suggested that it could be therapeutic for Aboriginal men to be able to see the communalities between their problems and those of non-Aboriginal offenders.

Some informants argued that even if the treatment groups themselves were to be racially integrated, it would be beneficial to have the Aboriginal members attend a collateral program focusing on issues of Aboriginal identity. Such programs have been piloted in Western Australia and have been very well-received by prisoners and recommended as a potent means of raising self-esteem.

In addition to the mixing of Aboriginal and non-Aboriginal participants, a number of informants raised the issue of whether urban and remote Aboriginals should be mixed. It was argued that in working with traditional men there were cultural issues of considerable complexity which needed to be handled in a sensitive and well-informed way; whereas the problems of urban Aboriginals could be dealt with in much the same way as those of non-Aboriginal offenders.

Another important issue highlighted by informants was the nature of the pre-existing relationships between individuals within the group. Three types of difficulty were identified as being more likely to arise among Aboriginal participants than non-Aboriginals. Firstly, in any given locality, there would be a substantial risk that an offender will encounter, in the treatment group, someone who has family connections with the victim of his crime. Self-disclosure in this context would be impeded not only by a sense of shame, but also fear of "payback." Secondly, there is the possibility that two members of the group might be from opposing sides of a family feud (which might have nothing to do with the offences which brought either of them into prison). Thirdly, where more traditional people are concerned, two members of the treatment group may be in a kinship connection which prohibits their speaking to each other (i.e., an avoidance relationship).

There was a general consensus that Aboriginal facilitators would have a strong advantage over non-Aboriginals in their ability to establish rapport with Aboriginal participants. Respondents highlighted two chief problems faced by non-Aboriginal workers. Firstly, they are likely to be regarded initially with suspicion, if not outright distrust and hostility. Again, this was construed as part of the natural legacy of colonization and marginalization. Secondly, clients might be reluctant to disclose to a non-Aboriginal about their circumstances and way of life, out of fear that they will be "looked down on." One suggestion was that it would be beneficial for non-Aboriginal facilitators to preface the main body of their program with a "de-coloniza- 
tion" initiative: an effort to address and hence defuse the negative feelings which clients are likely to bring to treatment with them.

In addition to considerations of rapport, it was suggested that Aboriginal facilitators would also have a better sense of how program content might need to be modified for delivery to Aboriginal clients. Some non-Aboriginal facilitators working in mixed groups had found that there were certain concepts which seemed alien and incomprehensible to Aboriginal participants. Such problems had arisen even among participants from urban settings. In some instances the difficulties in comprehension had remained despite facilitators' best efforts at explanation, thus leaving them with the impression that the problem was cultural in nature rather than merely one of vocabulary.

Overall, however, the prevailing view was that the difficulties faced by non-Aboriginal facilitators were substantial but by no means insurmountable. The great majority of the sample believed that non-Aboriginals could develop the capacity to relate to and work effectively with Aboriginal clients. While respondents generally emphasized the advantages which might be enjoyed by Aboriginal facilitators, they also acknowledged the potential difficulties which family connections might pose for such workers. If the worker comes from the same geographical region as his clients, it is very likely that he/she will have family connections with some members of the group, or with their victims. This could make for serious conflicts of interest and undermine the worker's objectivity.

Participants strongly endorsed the notion that literacy problems are common in Aboriginal offenders: in remote areas illiteracy was said to be virtually universal; among urban-based offenders, gross literacy problems were estimated to occur in $20-25 \%$ of those involved in treatment programs. This is consistent with Beresford and Omaji's (1995) suggestion that Aboriginal offenders will have more severe problems in the area of literacy and have a preferred learning style which is different from that of non-Aboriginal Australians. It was felt to be vital that program material be presented in a way that does not depend heavily on written information or assignments. Favored alternatives were videos, non-verbal symbols and role-plays.

Participants who had worked with urban clients recommended that formal didactic input be kept to a minimum and that the bulk of session time should be given over to discussion by the group as to how the issue raised by the facilitator applied in their own lives. Those who had worked in remote areas urged that abstract verbal concepts or principles expressed in English be minimized and that communication be couched in terms of concrete and personalized scenarios. It was also suggested that communication could be greatly assisted by use of occasional words in the group's predominant $\mathrm{Ab}$ original language, where this was within the facilitator's capabilities.

There was strong body of opinion that a prison-based program would not 
be effective on its own, divorced from the broader community: informants were adamant that maintenance of behavior change would depend on ongoing treatment/guidance as the offender attempted to reintegrate into his community. It was urged that post-release follow-up should actively involve key members of the offender's extended family, in view of the paramount importance of family ties among Aboriginal people. It was noted, for example, that in the typical domestic violence situation other members of the family would be directly involved and might therefore play key roles in the perpetuation or resolution of the conflict. In some remote communities a system of mentoring was still in place for younger men. Treatment-providers should therefore seek to link in with this traditional rehabilitative process at the release-planning stage.

\section{CONCLUSIONS AND RECOMMENDATIONS}

The criminological data suggest that, although there are large areas of overlap between Aboriginal and non-Aboriginal violent offenders, in some important ways Aboriginal offenders may have distinct characteristics that are important to program design. In particular, women are more likely to be victims of violence, and alcohol is more likely to play a role in offending. Programs for violent offenders should assess violence to spouses and the role of alcohol (even where index offences are of a different character), and include modules which explicitly address these two issues.

While Aboriginal men are dramatically overrepresented in Western Australian prisons, they are significantly underrepresented in current treatment programs for violent offenders. There are three possible causes, each with different implications for service planning and delivery: (a) there are relatively low proportions of Aboriginal offenders in the particular facilities where these programs are run; (b) many aboriginal offenders are being excluded on the grounds of poor English, poor literacy or acquired cognitive dysfunction; and (c) many Aboriginal offenders are simply opting out of participation.

The survey findings reported here are largely anecdotal, come from a small and possibly unrepresentative sample, and relate primarily to a Western Australian setting. Nevertheless, we would argue that surveying expert opinion in this way is a valuable way of developing understanding and producing preliminary research hypotheses which can be addressed systematically and on a larger scale in formal empirical studies. The survey responses provided insights into some of the predisposing and precipitant factors that are central to skills-based treatment and rehabilitation. These include both general issues of low self-esteem and attitudes towards violence, and specific antecedents of violence such as family feuds, sexual jealousy and alcohol use. Whilst these 
issues are commonly raised in programs, there may be a need to adapt materials so that they target and emphasize these areas.

Many suggestions were made by the interviewees as to ways of overcoming barriers to engagement in therapeutic programs. These included the use of all-Aboriginal treatment groups and Aboriginal facilitators or co-facilitators. Aboriginal counselling or support workers may be particularly valuable when an Aboriginal participant in a program is persistently passive, reticent, resistant or distressed for reasons which remain obscure to group-facilitators. As a general principle, feedback on course content should be actively solicited from Aboriginal participants, to identify parts of the program that need to be made more relevant or more compatible with Aboriginal values, norms and experiences. There was a consensus that program staff should receive cultural awareness education, and be offered ongoing support and advice from experts on Aboriginal cultures.

Another suggestion was to "market" programs by way of endorsement and promotion by other Aboriginal people. An Aboriginal liaison person could be conjointly involved at the point of first contact between the offender and program staff. The liaison person's role would be to give his/her perspective on the benefits of participation, help elicit any concerns the offender may have and provide reassurance as appropriate. Aboriginal offenders who have already successfully "graduated" from the program or workers from Aboriginal support agencies may be well qualified to take on this role.

It may also be useful for program facilitators to seek consultancy from Aboriginal service providers at the case-formulation stage. This would help ensure that they were achieving the richest possible understanding of the client's offending behaviour within its cultural context. This kind of consultancy is likely to be of greatest value in the more typical offence scenario where violence is intra-racial. However, even where the violence occurs in conjunction with a property crime against a non-Aboriginal victim, it is possible that cultural factors may contribute in a more subtle way, which a consultant may help to elucidate. Given a sufficiently large series of these expert-assisted formulations, it may be possible to draw out a number of recurrent themes and use these as a basis for the development of more generalized models of Aboriginal violent offending.

We hope that this paper has shed some light on potential key patterns, triggers and themes in Aboriginal violent offending and the cultural norms against which it takes place. A far better knowledge base will be necessary in order to ensure that rehabilitation programs are targeting the critical issues and dealing with them appropriately. The broader objective is to identify recurrent themes and distinctive features in the violent offending of the range of cultural groups that make up Australasian societies.

The paper was written to encourage discussion on how anger management 
and similar programs can be more responsive to the needs of different populations. Our suggestion is that Aboriginal violent offenders are likely to require a different emphasis in treatment and that particular attention should be given to the role of engagement in treatment. Ultimately this should lead to the development of more culturally appropriate curricula. In the interim, active efforts should be made to identify, within current programs, those modules, concepts or tasks which prove problematic or inappropriate for Aboriginal participants. Research is urgently needed to determine, in a more quantitative way, the distinctive antecedents for violence in particular cultural groups and to assess the effects of increasing the culture-appropriateness of programs on rehabilitation outcomes.

\section{REFERENCES}

Andrews, D.A. \& Bonta, J. 1994. The Psychology of Criminal Conduct. OH: Anderson.

Beck, R. \& Fernandez, E. 1998. Cognitive-behavioral therapy in the treatment of anger: A meta-analysis, Cognitive Therapy and Research, 22, 63-74.

Beresford, Q. \& Omaji, P. 1995. Rites of Passage: Aboriginal youth, crime and justice. South Fremantle: Fremantle Arts Centre Press.

Easteal, P. 1993. Killing the beloved: Homicide between adult sexual intimates. Canberra: Australian Institute of Criminology.

Edmondson, C.B. \& Conger, J.C. 1996. A review of treatment efficacy for individuals with anger problems: Conceptual, assessment and methodological issues. Clinical Psychology Review, 16, 251-275.

Harding, R. W., Broadhurst, R., Ferrante, A., \& Loh, N. 1995. Aboriginal contact with the criminal justice system and the impact of the Royal Commission into Aboriginal Deaths in Custody. Annandale, NSW: Hawkins Press.

Hazelhurst, K.M. 1987. Ivory Scales: Black Australia and the Law, University of New South Wales Press, Sydney.

Howells, K. 1996. The psychological management of violence in clinical and forensic settings: pitfalls and remedies, Psychiatry, Psychology and Law, 3, 71-76.

Howells, K., Watt, B., Hall, G. \& Baldwin, S .1997. Developing programs for violent offenders, Legal and Criminological Psychology, 2, 117-128.

Lincoln, R. and Wilson, P.1994. Aboriginal Offending: Patterns and Causes, In D. Chappell \& P. Wilson (Eds.) The Australian Criminal Justice System: The mid 1990s, Butterworths: Sydney.

Losel, F. 1996. Working with young offenders: the impact of meta-analyses. In C.R. Hollin \& K. Howells (Eds.) Clinical Approaches to Working with Young Offenders, Chichester: Wiley.

McGuire, J. (Ed.). 1995. What Works: Reducing Reoffending. Chichester: Wiley. National Committee on Violence. 1989. Violence in Australia. Canberra: Australian Institute of Criminology. 
Novaco, R. 1997. Remediating anger and aggression with violent offenders. Legal and Criminological Psychology, 2, 77-88.

Raphael, B. \& Swan, P. 1997. The mental health of Aboriginal and Torres Strait Islander people, International Journal of Mental Health, 26(3), 9-22.

Salmelainen, P. \& Coumelaros, C. 1993. Adult sexual assault in NSW. Sydney: NSW Bureau of Crime Statistics and Research.

Strang, H. 1993. Characteristics of homicide in Australia. In H. Strang and S. Gerull (Eds.), Homicide: Patterns, prevention and control. Proceedings of a conference held 12-14 May 1992. Canberra: Australian Institute of Criminology.

Walker, J. \& McDonald, D. 1995. The over-representation of indigenous people in custody in Australia. Trends and Issues in Crime and Criminal Justice, 47, $1-6$.

Ward, A. \& Baldwin, S. 1997. Violence and alcohol: the interface and intervention programs. An annotated bibliography. Unpublished report. Edith Cowan University, Perth, Western Australia.

Watt, B. \& Howells, K. 1998. Skills training for aggression control: Evaluation of an anger management program for violent offenders. Legal and Criminological Psychology, 4, 285-300.

\section{AUTHORS' NOTES}

Peter Mals works as a psychologist for the Forensic Team at Darwin Urban Mental Health Services, Darwin, Northern Territory, Australia.

Kevin Howells is professor of Forensic Psychology at the University of South Australia and chair of the Forensic and Applied Psychology Research Group. He has worked as a practitioner and academic in the fields of offender assessment, treatment and rehabilitation. He has a particular interest in the treatment of violence.

Andrew Day is a researcher at the University of South Australia. He has previously worked in offender treatment programs and in the prison systems in both the UK and Australia as a clinical and forensic psychologist. His current research interests include evaluations of correctional programs.

Guy Hall, a clinical psychologist, is a senior lecturer in Law at Murdoch University. His area of specialisation is the treatment of offenders; the identification and management of prisoners at risk of self-harm and suicide; and prisons.

The authors would like to thank Graham Chapman of the Ministry of Justice, Western Australia and the interview participants for their views on Aboriginal issues in relation to rehabilitation.

Address correspondence to Professor Kevin Howells, School of Psychology, University of South Australia, North Terrace, Adelaide 5000, South Australia. 